\title{
Luminal secretion of myo-inositol by the rat epididymis perfused in vitro*
}

\author{
T. G. Coopert, C. H. Yeung, W. Lui and C. Z. Yang \\ National Research Institute for Family Planning, Beijing, Peoples' Republic of China
}

\begin{abstract}
Summary. A technique for perfusing the lumen of rat epididymal tubules maintained in vitro showed that $\left[{ }^{3} \mathrm{H}\right]$ inulin was largely excluded from the lumen of unravelled tubules from the cauda and tubules from the corpus if the connective tissue capsule was removed. The preparation transported $\left[{ }^{3} \mathrm{H}\right]$ inositol from the bath fluid for $3 \mathrm{~h}$ against a concentration gradient in both regions with activity rising (16-29\% of bath fluid values) in the cauda and reaching a plateau $(18 \%)$ in the corpus epididymidis. HPLC showed that radioactivity was solely associated with inositol and its movement to the lumen was reduced by raising inositol in the bath fluid from $50 \mu \mathrm{M}$ (plasma levels) to $10 \mathrm{mM}$, but not affected by reducing the glucose concentration in the bath fluid or introducing physiological concentrations of inositol $(30 \mathrm{~mm})$ into the lumen. Secretion into the caudal lumen of unlabelled inositol measured by g.l.c. was maintained for $3 \mathrm{~h}$ at concentrations $(300 \mu \mathrm{M})$ greater than those in the bath fluid and was not reduced when glucose or inositol were removed from the bath. In contrast, glucose was only detectable in the lumen when it was present in the bathing medium, reaching $1 \%$ of this concentration. Radioactivity appeared in the epididymal lumen reaching a plateau $\left(19 \%\right.$ of bath fluid values) in the corpus and cauda when $\left[{ }^{3} \mathrm{H}\right]$ glucose was added to the bath fluid, but no radiolabelled inositol was found in the lumen. We conclude that epididymal tissue is a major source of secreted inositol.
\end{abstract}

\section{Introduction}

The high concentration of inositol in the epididymal lumen (Hinton, White \& Setchell, 1980) arises from concentration of inositol in testicular fluid by water resorption (Setchell \& Hinton, 1981), entry from the blood-stream (Hinton \& Howards, 1982) and secretion from an epithelial pool (Cooper, 1982). The extent of myo-inositol synthesis from glucose by the epididymis is debated (Eisenberg \& Bolden, 1964; Robinson \& Fritz, 1979; Maeda \& Eisenberg, 1980; Hasegawa \& Eisenberg, 1981) and although the potential exists, the contribution from luminal spermatozoa is not established (Roberts, Scouten \& Nyquist, 1976; Loewus, Wright, Bondioli, Bedgak \& Karl, 1983). Investigation of the relative importance of these possible sources would be facilitated by study of glucose uptake and conversion to inositol in vitro.

Luminal perfusion of a sperm-free epididymis has certain advantages over micropuncture in the study of epididymal function because spermatozoa, which may contribute to secretion, are removed and control of luminal fluid composition, which may affect transport across the epithelium, is permitted (Cooper \& Waites, 1980; Yeung, Cooper \& Waites, 1980). Transport studies would be further advanced if altering the composition of fluid bathing the tubules were possible, but this cannot easily be achieved in vivo. In-vitro experiments have shown that extratubular compounds influence uptake of carnitine into isolated tubules (Johansen \& Bøhmer, 1979), but the location of tracers within the tissue could not be ascertained. Two reports of in-vitro

\footnotetext{
* Reprint requests to Dr T. G. Cooper.

† Present address: Max Planck Society Clinical Research Unit, Steinfurter Strasse 107, D 4400 Munster, West Germany. 
luminal perfusion have indicated that ions and amino acids enter the proximal and distal epididymal lumen of boars and rats under both stop-flow and continuous perfusion (Dacheux, 1980; Wong, Au \& Ngai, 1980), but the extent to which entry of macromolecules reflected leakage of tubules damaged during dissection was not evaluated.

The present experiments were aimed at developing an in-vitro preparation which could be used to study both intra- and extra-tubular influences on the secretion of inositol and in particular to determine whether extratubular glucose is a precursor of secreted inositol.

\section{Materials and Methods}

Animals and procedure. Wistar-strain rats (mean \pm s.d. body weight $367 \pm 66 \mathrm{~g}$ ) had access to rat pellets (Institute of Genetics, Beijing) and water ad libitum, and were kept in $14 \mathrm{~h}$ light $/ 24 \mathrm{~h}$ at 18 $22^{\circ} \mathrm{C}$. Animals were anaesthetized with urethane (ethyl carbamate, $1 \mathrm{~g} / \mathrm{kg}$ ) and sequentially each epididymis was transferred to ice-cold medium, stripped of adhering fat and the distal cauda and mid-corpus were separated. In all experiments the outer connective tissue capsule was rapidly but carefully removed and the lobes of tubule coils were gently pulled apart along natural planes of cleavage. In some experiments further unravelling of the tubule was accomplished. The distal end of the tubule was cannulated with polyvinylchloride tubing $(0.5 \mathrm{~mm}$ i.d., $0.8 \mathrm{~mm}$ o.d.; Dural Plastics Pty \& Eng Co., Dural, New South Wales, Australia) or polyethylene tubing ( $0.6 \mathrm{~mm}$ i.d., $1.0 \mathrm{~mm}$ o.d.; Intramedic, Clay-Adams, Parsippany, NJ, U.S.A.) the diameters of which were reduced over a flame to approximate the diameter of the tubule to be cannulated, and tied in place with $4 / 0$ silk thread suture for the cauda or $7 / 0$ thread for the corpus. After flushing out the luminal contents with solutions subsequently used in the perfusion (intraluminal fluid) another cannula was inserted into the more proximal end and secured with $7 / 0$ thread (Barraquer, John Weiss \& Son Ltd, London W1H ODN, U.K.). When necessary, about $150 \mu \mathrm{l}$ of perfusing solution were flushed through manually in 1-2 min and aliquants of the last flush-out fluid were collected. About 45$60 \mathrm{~min}$ after removal from the animal the sperm-free cannulated tubule was transferred to a $20-\mathrm{ml}$ water-jacketed organ bath (Harvard Aparatus Ltd, Edenbridge TN6 6HE, U.K.) maintained at 33 $\pm 1^{\circ} \mathrm{C}$ and containing fluid continuously bubbled with air drawn through a Millipore filter $(0.45 \mu \mathrm{m}$ pore diameter). Continuous perfusion through the lumen was maintained at a nominal rate of $1 \mu \mathrm{l} / \mathrm{min}$ (Harvard Infusion pump, Model 975A, South Natick, MA, U.S.A.); at this rate the times needed for complete flow through the entire corpus and cauda tubules were about 6 and $25 \mathrm{~min}$ respectively. The outflowing perfusate was collected every $30 \mathrm{~min}$ into preweighed vials to ascertain exact perfusion rates. At the end of the experiment the tubules were fixed by luminal injection of $1.5 \%$ aqueous glutaraldehyde containing $0.1 \%$ amido black $10 \mathrm{~B}$ in $7 \%$ acetic acid $(\mathrm{v} / \mathrm{w} / \mathrm{v})$, unravelled and their lengths were measured.

Solutions. All chemicals were from the Sigma Chemical Company (Poole BH17 7NH, U.K.) unless otherwise stated. The bath fluid consisted of $127 \mathrm{mM}-\mathrm{NaCl}, 2.7 \mathrm{~mm}-\mathrm{KCl}, 8 \cdot 1 \mathrm{mM}-\mathrm{Na}_{2} \mathrm{HPO}_{4}$, $1.5 \mathrm{~mm}-\mathrm{KH}_{2} \mathrm{PO}_{4}, 0.1 \mathrm{~mm}-\mathrm{Na}_{4}$ EDTA, $0.5 \mathrm{~mm}-\mathrm{MgSO}_{4}, 0.8 \mathrm{~mm}-\mathrm{CaCl}_{2}, 5 \mathrm{~mm}$-D-glucose, $10 \mathrm{~mm}-$ sodium DL-lactate, $5 \mathrm{mM}$-sodium pyruvate, $50 \mu \mathrm{M}$-myo-inositol, $30 \mu \mathrm{M}$-L-carnitine (a gift from Sigma Tau, Industrie Farmaceutiche Riunite SPA, 0014 Rome, Italy), $1 \mathrm{mg}$ bovine serum albumin $/ \mathrm{ml}, 50$ $\mathrm{ng}$ testosterone $/ \mathrm{ml}$ (final ethanol concentration $0.005 \% \mathrm{v} / \mathrm{v}$ ) with 50 i.u. $\mathrm{K}^{+}$penicillin $/ \mathrm{ml}$ and 50 i.u. streptomycin sulphate $/ \mathrm{ml}$; the osmolarity was $305 \mathrm{mosmol} / \mathrm{kg}$ water and the $\mathrm{pH}$ was $7 \cdot 4$. Intraluminal fluid for the cauda contained $13 \mathrm{~mm}-\mathrm{NaCl}, 50 \mathrm{~mm}-\mathrm{KCl}, 2.6 \mathrm{~mm}-\mathrm{CaCl}_{2}, 1 \cdot 1 \mathrm{~mm}-$ $\mathrm{MgSO}_{4}, 18 \mathrm{~mm}-\mathrm{N}$-morpholinopropanesulphonic acid and was adjusted to $\mathrm{pH} 6.9$ with $7 \mathrm{~mm}$ $\mathrm{NaOH}$. To raise the osmolarity to $340 \mathrm{mosmol} / \mathrm{kg}$ water, $77 \mathrm{~mm}$-choline chloride was included. The solution used for the corpus was similar but concentrations were adjusted to $51 \mathrm{~mm}-\mathrm{NaCl}, 37 \mathrm{mM}$ $\mathrm{KCl}$ and $80 \mathrm{~mm}$-choline chloride. Composition of the bathing medium was altered by omitting or reducing glucose to $0.5 \mathrm{~mm}$ or increasing myo-inositol to $10 \mathrm{~mm}$ with isosmotic changes in the 
amount of $\mathrm{NaCl}$. The intraluminal fluid was altered by adding $30 \mathrm{~mm}-m y o$-inositol or $25 \mathrm{~mm}$ glucose and making isosmotic reduction in choline chloride.

Isotopes and liquid scintillation counting. The following isotopes from Amersham International (Amersham HP7 9LL, U.K.) were added to the bath fluid at the following concentrations and final specific activities: $\left[{ }^{3} \mathrm{H}\right]$ inulin $(0 \cdot 3 \mu \mathrm{Ci} / \mathrm{ml} ; 2 \cdot 42 \mathrm{Ci} / \mathrm{mol})$, myo- $\left[2-{ }^{3} \mathrm{H}\right]$ inositol $(0.75 \mu \mathrm{Ci} / \mathrm{ml} ; 15$ and $0.075 \mathrm{Ci} / \mathrm{mol})$ and $\mathrm{D}-\left[2-{ }^{3} \mathrm{H}\right] \mathrm{glucose}(0.8 \mu \mathrm{Ci} / \mathrm{ml}: 0 \cdot 16,1.6$ and $17000 \mathrm{Ci} / \mathrm{mol})$. Duplicate $10 \mu \mathrm{l}$ aliquants of outflowing perfusate, inflowing perfusate and bath fluids were transferred to $5 \mathrm{ml}$ or $2 \mathrm{ml}$ scintillation fluid (5.5 g PPO, 0.1 g POPOP per litre of toluene: Triton X-100 $67: 33, \mathrm{v} / \mathrm{v}$ ) giving unquenched efficiencies for ${ }^{3} \mathrm{H}$ of $32 \%$ and $37 \%$ respectively. Radioactivity was monitored on an LKB Rackbeta 1217 with quench correction by external standardization. Remaining samples were pooled and frozen at $-70^{\circ} \mathrm{C}$. Results were expressed as concentrations of radioactivity in the luminal perfusate as a percentage of that in the bath, or corrected for length of the tubule. When plateau values were attained mean values for the period were calculated for each epididymis. Statistical analysis was by Student's $t$ test. Transport rates of inositol and glucose were calculated from the perfusion rate, concentration of isotope in the lumen and the specific activity in the bath.

High-performance liquid chromatography (HPLC). Separation of radiometabolites was effected by HPLC using a Perkin-Elmer Series 3B chromatograph, a $25 \mathrm{~cm} \times 4.6 \mathrm{~mm}$ column of Silica B-5 ( $7 \mu \mathrm{m}$, Perkin-Elmer) with a $2 \mathrm{~cm}$ guard column of LC-Si (Supel Co. Inc.). Isocratic elution at $2 \mathrm{ml} /$ min and $20^{\circ} \mathrm{C}$ was by acetonitrile (Merck HPLC grade) : water (deionized, triple-distilled) : tetraethylene pentamine (reagent grade, Shanghai First Reagent Factory) (72:28:0.02, by vol.) made to pH 8.9 with acetic acid. Detection of eluting substances was by a differential refractive index monitor (Laboratory Data Control, Model 11071, NH, U.S.A.). Pooled samples of perfusates and bath, deproteinized with 2 volumes of ethanol, were concentrated by freeze-spinning (Labconco Corp., Kansas City, MO, U.S.A.) and taken up in water. After centrifugation at $13000 \mathrm{~g}_{\max }$ for 5 min, 20-25 $\mu$ l were injected and fractions were collected with an LKB Ultrorac 2070 at $0 \cdot 3-\mathrm{min}$ intervals at the outflow of the refractive index monitor. From each fraction, $0.5 \mathrm{ml}$ with $0.5 \mathrm{ml}$ water, or $0.15 \mathrm{ml}$, was added to $5 \mathrm{ml}$ or $2 \mathrm{ml}$ scintillant respectively for estimation of tritium.

Gas-liquid chromatography (g.l.c.). Samples were deproteinized with two volumes of ethanol containing 20 or $100 \mathrm{nmol}$ internal standard (methyl-4,6-O-benzylidine $\alpha$-D-glucopyranoside, MBG) and supernatants were taken to dryness in vacuo over $\mathrm{P}_{2} \mathrm{O}_{5}$. After addition of $25-50 \mu 1$ silylating reagent (trimethylsilylimidazole (Janssen Chimica, B-2340 Beerse, Belgium): dry toluene, $1: 2, \mathrm{v} / \mathrm{v}$ ), samples were heated at $45^{\circ} \mathrm{C}$ for $60 \mathrm{~min}$ before injection. Silyl derivatives of carbohydrates were quantified by g.l.c. on a Shimadzu GC-RIA. Separation was effected in $2.6 \mathrm{~m}$ $\times 3 \mathrm{~mm}$ glass columns of $3 \% \mathrm{SE}-30$ on Gas Chrom Q (80-120 mesh) and detection was by flame ionization. Filtered carrier gas $\left(\mathrm{N}_{2}\right)$, hydrogen and air were supplied at 60,47 and $300 \mathrm{ml} / \mathrm{min}$ respectively. The detection temperature was $250^{\circ} \mathrm{C}$ and the oven temperature was programmed to rise after $8 \mathrm{~min}$ at $190^{\circ} \mathrm{C}$ to $210^{\circ} \mathrm{C}$ at $3.5^{\circ} \mathrm{C} / \mathrm{min}$. This separated $\alpha$ - and $\beta$-glucose from inositol (retention times $0.449,0.622$ and 0.814 relative to $\mathrm{MBG}$ ). Over the range $10-100 \mathrm{nmol}$, recoveries of glucose and inositol were $108 \%$ and $105 \%$ and coefficients of variation between assays were $9 \cdot 2 \%$ and $9.0 \%$, respectively.

\section{Results}

Movement of radio-labelled compounds to the lumen

$\left[{ }^{3} \mathrm{H}\right]$ Inulin. Tritium appeared in the lumen from the bath solutions containing $\left[{ }^{3} \mathrm{H}\right]$ inulin. In the cauda (mean \pm s.d. perfused length $17.0 \pm 4.7 \mathrm{~cm}$ ) there was little difference in the extent of entry whether the tubules were unravelled $(5.8 \%$ of the bath fluid values at $3 \mathrm{~h})$ or not $(4.1 \%)$ and the pooled results are plotted in Text-fig. 1. By contrast, the corpus epididymidis (length $8.6 \pm 1 \cdot 8 \mathrm{~cm}$ ) 


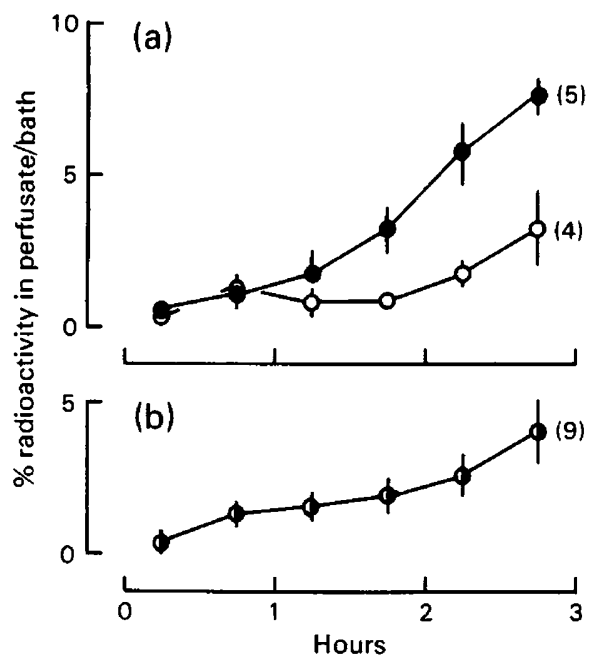

Text-fig. 1. The concentration of radioactivity in fluid in the epididymal lumen during perfusion in vitro, expressed as a percentage of that in the bath fluid containing $\left[{ }^{3} \mathrm{H}\right]$ inulin for epididymal tubules of (a) the corpus and (b) the cauda. Tubules were unravelled (O) or with capsule only removed $(O)$. Each point is the mean \pm s.e.m. for the no. of experiments indicated in parentheses.

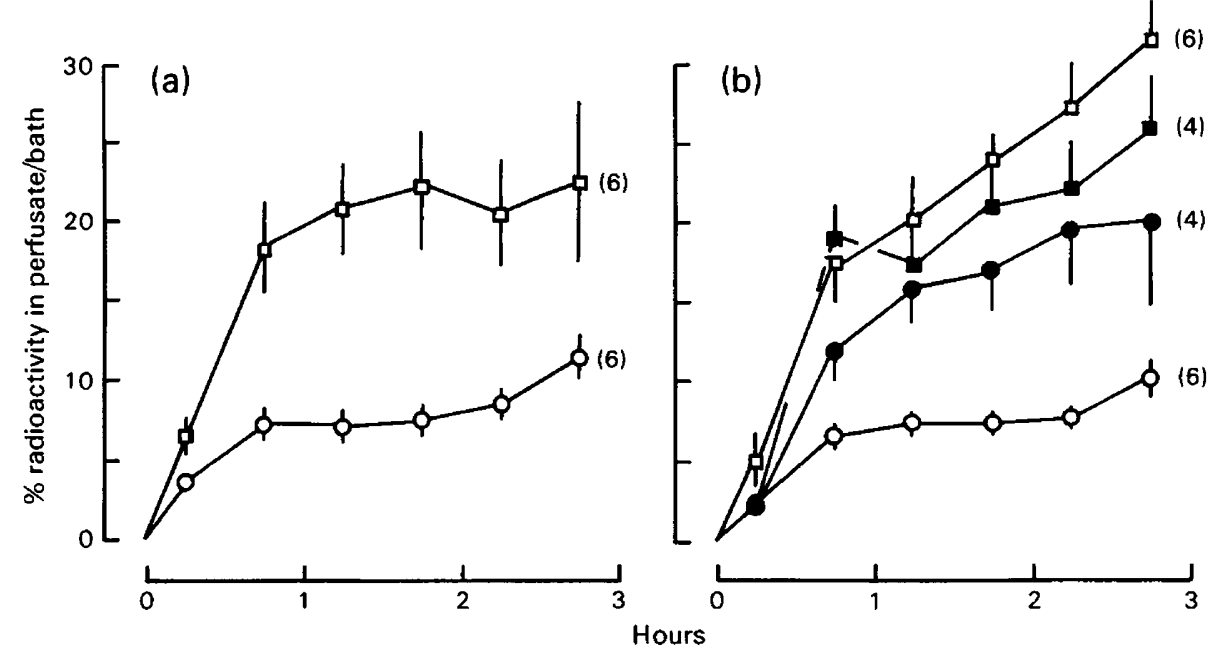

Text-fig. 2. The concentration of radioactivity in fluid in the epididymal lumen during perfusion in vitro expressed as a percentage of that in the bath fluid containing $\left[{ }^{3} \mathrm{H}\right]$ inositol for epididymal tubules of (a) the corpus and (b) the cauda. $\square, 0$ : Inositol-free fluid in the lumen and bath fluid containing $5 \mathrm{mM}$-glucose and $50 \mu \mathrm{M}(\square)$ or $10 \mathrm{mM}(\mathrm{O})$ inositol. $\square, 0$ : Glucosefree bath medium containing $50 \mu \mathrm{M}$-inositol and fluid in the lumen containing either no inositol (a) or $30 \mathrm{~mm}$-inositol (O). Each point is the mean \pm s.e.m. for the no. of experiments indicated in parentheses.

proved to be delicate and unravelling the tubule resulted in significantly greater radioactivity in the lumen $(3.3 \%$ bath fluid values by the end of the 2 nd hour of perfusion) than if the tubules were not unravelled $(0.9 \%, P<0.05)$ and this trend continued over the next hour (see Text-fig. 1). In all subsequent experiments, therefore, only the capsule was removed from the corpus epididymidis. 
$\left[{ }^{3} \mathrm{H}\right]$ Inositol. In medium of composition similar to that of blood plasma and containing $50 \mu \mathrm{M}-$ inositol and $5 \mathrm{~mm}$-glucose, radioactivity entered the caudal lumen (length $17.0 \pm 4.3 \mathrm{~cm}$ ) to reach levels at the end of $3 \mathrm{~h}(28.5 \%$ those of the bath fluid) that were significantly greater than those obtained after $1 \mathrm{~h}(16.4 \% ; P<0.01)$, a gradual increase of $2.4-4.0 \%$ of bath fluid values per 30 -min period (see Text-fig. 2). In contrast, radioactivity in the corpus lumen $(9.0 \pm 3.0 \mathrm{~cm}$ long) reached a plateau over the same period $(17 \cdot 7-22.8 \%$ of bath fluid values, mean $20.6 \%$ but was not significantly different from entry into the cauda at any time. When results were expressed per unit length, entry into the corpus only significantly exceeded that into the cauda up to $1.5 \mathrm{~h}(P<0.05)$.

When the concentration of inositol in the bath was raised to $10 \mathrm{~mm}$ there was a $60-70 \%$ reduction in movement of tracer to the lumen in both the cauda and corpus epididymidis, and between 1 and $2.5 \mathrm{~h}$ activity reached a plateau $6.7-7.8 \%$ bath (mean $7.4 \%$ ) in the cauda which was not different from that $(7 \cdot 3-8.6 \%$, mean $7.7 \%$ ) in the corpus (Text-fig. 2). There was no difference in the uptake of $\left[{ }^{3} \mathrm{H}\right]$ inositol in the cauda from glucose-free bath solutions containing $50 \mu \mathrm{M}$-inositol $(17.5-26.2 \%$ of bath fluid values from $1-3 \mathrm{~h}$ perfusion, rising at $1.8 \%$ of the bath fluid value per 30 $\mathrm{min}$ ) or those in the presence of glucose (Text-fig. 2b). However, there was consistently less transport of $\left[{ }^{3} \mathrm{H}\right]$ inositol when $30 \mathrm{~mm}$-inositol was added to solutions perfusing the caudal lumen, but this was only significant $(P<0.05)$ at $1 \mathrm{~h}$; thereafter activity continued to increase in the lumen at $2 \%$ of bath fluid values per $30 \mathrm{~min}$ (Text-fig. $2 \mathrm{~b}$ ).

$\left[{ }^{3} \mathrm{H}\right]$ Glucose. Entry of radioactivity to the caudal lumen $(16.6 \pm 3.9 \mathrm{~cm}$ long) from solutions containing $5 \mathrm{~mm}$-glucose reached a plateau at $17 \cdot 3-19.7 \%$ (mean $18.9 \%$ of bath fluid values). Lowering the glucose concentration to $0.5 \mathrm{~mm}$ increased entry, and when no glucose additional to the tracer was added to the bath fluid, significantly greater amounts of radioactivity reached the lumen by $2-3 \mathrm{~h}(P<0.001)$. Entry into the corpus epididymidis $(6.3 \pm 2.8 \mathrm{~cm}$ long $)$ was similar (mean 19.4\%) to that in the cauda; but there was no consistent trend in transport when glucose concentrations were varied (Text-fig. 3). When glucose was present in the cauda epididymal lumen ( $25 \mathrm{mM}$ ) movement of tracer to the lumen was consistently increased (Text-fig. 3) and significantly so at 0.5 and $1 \mathrm{~h}(P<0.05)$, reaching a value obtained in glucose-free media.

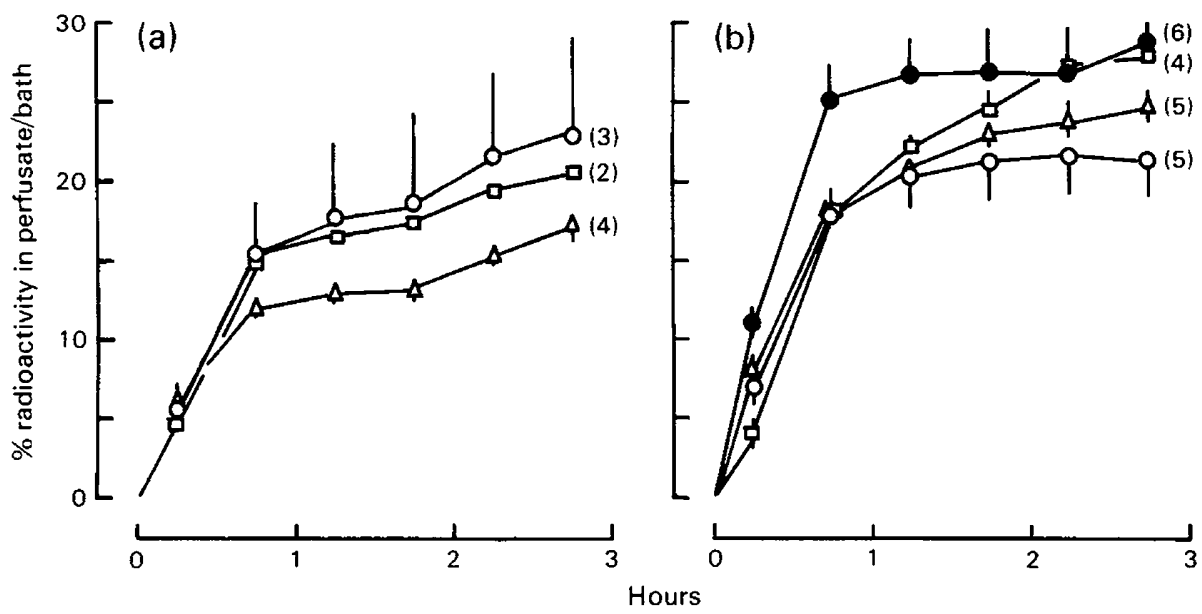

Text-fig. 3. The concentration of radioactivity in fluid in the rat epididymal lumen during perfusion in vitro expressed as a percentage of that in the bath fluid containing $\left[{ }^{3} \mathrm{H}\right]$ glucose for epididymal tubules of (a) the corpus and (b) the cauda. $O, \square, \triangle:$ Glucose-free fluid in the lumen and bath fluid containing $50 \mu \mathrm{M}$-inositol and $50 \mathrm{nM}(\square), 500 \mu \mathrm{M}(\triangle)$ or $5 \mathrm{mM}(O)$ glucose. - Bath fluid containing $5 \mathrm{~mm}$-glucose and $50 \mu \mathrm{M}$-inositol and fluid in the lumen containing 25 mM-glucose. Each point is the mean \pm s.e.m. for the no. of experiments indicated in parentheses. 
Analysis of radiometabolites

The HPLC procedure employed adequately separated glucose (retention time $5 \mathrm{~min} 08 \mathrm{sec}-5$ $\min 13 \mathrm{sec}$ ) and $m y o$-inositol $(8 \mathrm{~min} 06 \mathrm{sec}-8 \mathrm{~min} 14 \mathrm{sec}$ ) from the solvent front $(1 \mathrm{~min} 59 \mathrm{sec}-2 \mathrm{~min}$ $02 \mathrm{sec}$ ). Labelled standards added to the perfusing solution co-chromatographed with unlabelled compounds, fractions being collected slightly later than mass peaks owing to the dead space between the refractive index detector and fraction collector $\left(\left[{ }^{3} \mathrm{H}\right]\right.$ glucose at $5 \mathrm{~min} 06 \mathrm{sec}-5 \mathrm{~min} 24$ sec and $\left[{ }^{3} \mathrm{H}\right]$ inositol at $8 \mathrm{~min} 06 \mathrm{sec}-8 \mathrm{~min} 24 \mathrm{sec}$ ).

$\left[{ }^{3} \mathrm{H}\right]$ Inositol in bath. The majority of radioactivity in the bath at the end of the 3-h perfusion migrated with myo-inositol and accounted for $92 \%$ of the total radioactivity. Only one peak of activity comigrating with authentic inositol appeared in the perfusates from the corpus and cauda, accounting for $91 \%$ of the total activity in the cauda and $84 \%$ in the corpus from pooled perfusates, and $79 \%$ in the cauda in one experiment in which all the perfusate was collected for metabolite analysis.

$\left[{ }^{3} \mathrm{H}\right]$ Glucose in bath. One major peak of radioactivity which migrated with $\left[2-{ }^{3} \mathrm{H}\right] \mathrm{glucose}$ was present in the bath and comprised $81 \%$ of the total bath activity. By contrast, two major peaks of radioactivity were present in the perfusates from both corpus and cauda. Of these, the major peak comigrated with glucose (44 and 55\% total luminal activity in cauda ( 2 exps) and $59 \%$ in corpus). The smaller peak eluted at $9 \mathrm{~min} 18 \mathrm{sec}-10 \mathrm{~min} 12 \mathrm{sec}$ (later than water and myo-inositol) and comprised 12 or $23 \%$ total activity in the caudal lumen and $13 \%$ in the corpus. The metabolite was not identified.

\section{Transport of inositol from the bath into the lumen of the epididymis}

Although the movement of tracer to the lumen was reduced when inositol concentrations in the bathing fluid were raised 200-fold (Text-fig. 2), the net flux of inositol to the lumen was increased, but by a smaller margin: 57-fold in the cauda and 87-fold in the corpus (Table 1). Total secretion rates were not significantly different in the corpus and cauda and were not directly related to length of the tubule. Secretion per unit length in the corpus epididymidis significantly exceeded that by the cauda in the presence of $10 \mathrm{~mm}$-inositol $(P<0.002)$. Omitting glucose from the bathing fluid or adding inositol to the fluid perfusing the lumen did not significantly alter the total amount of inositol transported in $3 \mathrm{~h}$ (Table 1).

Table 1. Transport of myo-inositol from bath medium to the rat epididymal lumen during perfusion in vitro

\begin{tabular}{|c|c|c|c|c|c|c|}
\hline \multirow{2}{*}{\multicolumn{2}{|c|}{ In bath fluid }} & \multirow{3}{*}{$\frac{\text { In lumen }}{\begin{array}{c}\text { Inositol } \\
(\mathrm{mM})\end{array}}$} & \multicolumn{4}{|c|}{ Total transport } \\
\hline & & & \multicolumn{2}{|c|}{$\mathrm{nmol} / 3 \mathrm{~h}$} & \multicolumn{2}{|c|}{$\mathrm{nmol} / 3 \mathrm{~h} / \mathrm{cm}$} \\
\hline $\begin{array}{c}\text { Inositol } \\
(\mathrm{mM})\end{array}$ & $\underset{\text { (mM) }}{\text { Glucose }}$ & & Cauda & Corpus & Cauda & Corpus \\
\hline 0.05 & $5 \cdot 0$ & 0 & $1.98 \pm 0.17(7)$ & $1.65 \pm 0.21(6)$ & $0.114 \pm 0.012(7)$ & $0.154 \pm 0.017(6)$ \\
\hline 10.0 & $5 \cdot 0$ & 0 & $114 \pm 15(6)$ & $143 \pm 15(6)$ & $6.60 \pm 1 \cdot 14(6)$ & $14.92 \pm 1.44(6)$ \\
\hline 0.05 & 0 & 0 & $1.56 \pm 0.28(4)$ & - & $0.115 \pm 0.018(4)$ & - \\
\hline 0.05 & 0 & 30 & $1.39 \pm 0.30(5)$ & - & $0.084 \pm 0.021$ & - \\
\hline
\end{tabular}

Values are mean \pm s.e.m. for the no. of experiments in parentheses.

\section{Transport of glucose from the bath to the lumen of the epididymis}

When glucose concentrations in the bath were increased 11000 times from tracer levels to 500 $\mu \mathrm{M}$, the flux into the lumen increased by a similar amount: 9700 -fold in the cauda and 8900 -fold in the corpus. Raising the concentration a further 10-fold also increased transport to the lumen 10-fold in the cauda and 12-fold in the corpus (Table 2). Raising glucose concentrations in the lumen did 
Table 2. Transport of glucose from bath medium to the rat epididymal lumen during perfusion in vitro

\begin{tabular}{|c|c|c|c|c|c|}
\hline \multirow{3}{*}{$\frac{\text { In bath }}{\substack{\text { Glucose } \\
\text { (mM) }}}$} & \multirow{3}{*}{$\frac{\text { In lumen }}{\begin{array}{c}\text { Glucose } \\
\text { (mM) }\end{array}}$} & \multicolumn{4}{|c|}{ Total transport } \\
\hline & & \multicolumn{2}{|c|}{$\mathrm{nmol} / 3 \mathrm{~h}$} & \multicolumn{2}{|c|}{$\mathrm{nmol} / 3 \mathrm{~h} / \mathrm{cm}$} \\
\hline & & Cauda & Corpus & Cauda & Corpus \\
\hline $50 \times 10^{-6}$ & 0 & $1.75+0.25^{*}(4)$ & $1.31+0.06^{*}(2)$ & $0.10+0.01^{*}(4)$ & $0.32+0.14^{*}(2)$ \\
\hline 0.5 & 0 & $16.9 \pm 1.4(5)$ & $11.6 \pm 0.9(4)$ & $1.11 \pm 0.20(5)$ & $2.60 \pm 0.80(4)$ \\
\hline $5 \cdot 0$ & 0 & $175 \pm 16(5)$ & $139 \pm 46(3)$ & $11 \cdot 1 \pm 2 \cdot 2(4)$ & $22 \cdot 3 \pm 12 \cdot 0(3)$ \\
\hline $5 \cdot 0$ & 25 & $189 \pm 23(6)$ & - & $17.7 \pm 1.9(6)$ & - \\
\hline
\end{tabular}

Values are mean \pm s.e.m. for no. of experiments in parentheses.

* Units are pmol not nmol.

not significantly increase transport to the lumen and there were no significant differences in secretion between corpus and cauda under similar conditions even when length was taken into account (Table 2).

\section{Total secretion of unlabelled inositol and glucose into the lumen of the cauda epididymidis}

In these experiments the tubules perfused were $17.9 \pm 1 \cdot 1 \mathrm{~cm}$ long. Inositol detected by g.l.c. appeared in the first samples of luminal fluid in all 12 experiments in which inflowing perfusion fluid was shown to be free of inositol. Its concentration did not decline during $3 \mathrm{~h}$ (data not shown), and the mean values from 3-h samples obtained from each epididymis are given in Table 3 . These total secretion rates are from 20 to 36 times higher than the rates of transport from the bath (Table 1) and secretion was not consistently reduced when glucose or inositol were omitted from the bath. The mean \pm s.e.m. concentration of inositol $(300 \pm 27 \mu \mathrm{M}, n=28)$ was 6 times greater than that present in the bathing fluid.

Glucose only appeared in luminal fluid when it was present in the bathing medium. Its mean \pm s.e.m. concentration $(64 \pm 17 \mu \mathrm{M}, n=12)$ was only $1.3 \%$ of that in the bath and secretion rates, $11.55 \pm 3.79 \mathrm{nmol} / 3 \mathrm{~h}$ or $0.81 \pm 0.31 \mathrm{nmol} / 3 \mathrm{~h} / \mathrm{cm}$, were about $7 \%$ of those estimated to be transported from the bath (Table 2).

Table 3. Secretion of myo-inositol into the lumen of the rat epididymal lumen during perfusion in vitro

\begin{tabular}{|c|c|c|c|c|}
\hline \multirow{2}{*}{\multicolumn{2}{|c|}{ In bath fluid }} & \multicolumn{3}{|c|}{ Luminal perfusate } \\
\hline & & \multirow[b]{2}{*}{$\begin{array}{c}\text { Concentration } \\
(\mu \mathrm{M})\end{array}$} & \multicolumn{2}{|c|}{ Secretion } \\
\hline $\begin{array}{c}\text { Inositol } \\
(\mu \mathrm{M})\end{array}$ & $\begin{array}{l}\text { Glucose } \\
\text { (mM) }\end{array}$ & & $\mathrm{nmol} / 3 \mathrm{~h}$ & $\mathrm{nmol} / 3 \mathrm{~h} / \mathrm{cm}$ \\
\hline 50 & 5 & $352 \pm 69$ & $66 \cdot 6+13 \cdot 1$ & $4 \cdot 14+0.82$ \\
\hline 50 & 0 & $221 \pm 36$ & $38 \cdot 0+6 \cdot 0$ & $2 \cdot 29+0.33$ \\
\hline 0 & 0 & $384 \pm 36$ & $70 \cdot 0 \pm 5 \cdot 2$ & $3.51 \pm 0.42$ \\
\hline
\end{tabular}

Values are mean \pm s.e.m. for 4 experiments.

\section{Discussion}

The epididymal preparation described here, where the environment on the two sides of the epithelium can be controlled, can be used to examine metabolism and directional transport across epididymal cells whose polarity in the epithelium is maintained. Inulin is an established marker that does not cross the rat blood-epididymal barrier (Cooper \& Waites, 1979; Hinton \& Howards, 
1981 ; Hoffer \& Hinton, 1984), so its low movement to the lumen, even when the cauda tubule was unravelled, indicates that there was not gross damage to the tubule during manipulation, and that maintaining the normal tubule configuration did not limit access of $\left[{ }^{3} \mathrm{H}\right]$ inulin to the epithelium. That activity in the lumen of the corpus epididymidis was greater in the unravelled than the undissected tubules, suggests that focal damage can occur during preparation of a tubule that is less protected than the cauda by peritubular muscle (Reid \& Cleland, 1957). Leakage to the extent observed may severely compromise estimates of water resorption made in vitro using inulin as a volume marker (Wong et al., 1980; Cooper, Yeung \& Wu, 1985). An alternative explanation for the increased entry of $\left[{ }^{3} \mathrm{H}\right]$ inulin into unravelled tubules, that unravelling the tubules exposes them more to the bathing fluid, is not supported by three lines of evidence. Firstly, the mid-corpus region is only two tubules thick, so at least one side of each coil would be exposed to the medium. Secondly, the entry of tracer should be less rapid than in unravelled tubules and should continue until it reaches the plateau expected in the more accessible tissue and neither finding is supported by the data. Thirdly, access of tracer to the base of the epithelium is not limited because inositol and glucose entered the lumen to greater extents, and the extent and rate of movement of the former were similar to those obtained from an in-vivo preparation (Cooper, 1982) in which the excellent microvasculature of the epididymis (Kormano, 1968; Suzuki, 1982) is preserved.

The slowly rising activity of $\left[{ }^{3} \mathrm{H}\right]$ inositol in the cauda lumen during perfusion suggests slow equilibration of tracer with a large pool of inositol as concluded from in-vivo experiments (Cooper, 1982). For the first time, data are presented for the corpus epididymidis in which luminal radioactivity from bath $\left[{ }^{3} \mathrm{H}\right]$ inositol reached a plateau. Since the failure to reach a plateau in the cauda cannot be explained by its longer time for turnover of the luminal volume ( $25 \mathrm{~min}$ ) compared to the corpus ( $6 \mathrm{~min}$ ), and assuming equal densities of pumps in the 2 regions, the data suggest that tissue pools of inositol were less in the corpus than in the cauda, as are concentrations in the lumen (Hinton et al., 1980).

In both regions the transport of $\left[{ }^{3} \mathrm{H}\right]$ inositol occurred against a concentration gradient and was reduced when bath concentrations of inositol were raised, indicating the presence of membrane carriers, most probably associated with active pumps in the basal part of the epithelium. Increasing plasma concentrations of inositol similarly reduced transfer of circulating $\left[{ }^{3} \mathrm{H}\right]$ inositol to the rat caput epididymal lumen (Hinton \& Howards, 1982). Transport of $\left[{ }^{3} \mathrm{H}\right]$ inositol in the cauda was not altered when glucose was removed from the bath, so carriers are likely to be specific for inositol and energy for the pump is not derived solely from extratubular glucose.

The extent of transfer in $\left[{ }^{3} \mathrm{H}\right]$ inositol could provide at most a luminal concentration of $12.5 \mu \mathrm{M}$, and although specific activity measurements were not made on individual samples, an estimate calculated from the relative concentrations of labelled and unlabelled inositol in the caudal lumen and bath at the end of perfusion is that luminal activity is $4 \%$ of that in the bath, close to that measured in vivo (3\%: Cooper, 1982). The rate of inositol transport from the bath was indeed insufficient to account for the total secreted inositol measured by g.l.c., confirming the presence of large amounts of unlabelled inositol in the tissue. The in-vitro preparation can be used to locate the source of this inositol. The continued secretion of inositol when no glucose or inositol were provided in the bathing medium confirms the insignificant contribution of extratubular inositol, as inferred above, and rules out bath glucose as an immediate precursor. However, it is not possible to decide whether epithelial inositol arises from endogenous pools or by synthesis. In the absence of synthesis it can be calculated from histological measurements (Reid \& Cleland, 1957) that an epithelial cell concentration of $17 \mathrm{mM}$ would have to be depleted over $3 \mathrm{~h}$ to sustain the secretion rate observed during that time. The highest concentration, if diffusion were to account for movement from cell to lumen, would be that found in the lumen in vivo (30-50 mM: Hinton et al., 1980; Cooper, 1982). Neither of these concentrations are likely to support the constant secretion observed in this study, and this argues for the biosynthesis of secreted inositol or intracellular concentrations in excess of $50 \mathrm{~mm}$. 
The presence of metabolites of glucose in the lumen, but not bath, indicated tht the tissue supported metabolism, but in the present study no conversion to inositol was demonstrated. In other studies there was also no synthesis of inositol from glucose (Eisenberg \& Bolden, 1964) or glucose 6-phosphate (W. C. L. Ford, personal communication) in epididymal homogenates. The activity of inositol synthase reported by Robinson \& Fritz (1979) exceeds the activity of phosphoglucose isomerase 12-fold (Brooks, 1976a), using the epididymal protein content given by Brooks (1976b), so loss of tritium from the $\mathrm{C}_{2}$-position of glucose 6-phosphate during glycolysis (Hammerstedt, 1975) should be minimal, although the conflicting reports on the activity of the relevant enzymes in rat epididymal tissue (Robinson \& Fritz, 1979; Maeda \& Eisenberg, 1980; Hasegawa \& Eisenberg, 1981) need clarification and bear directly on the results of this study. The observations may also relate to the presence of endogenous pools of metabolites which were not equilibrated during the experiments, although work on tissue slices indicates that intracellular glucose is very low in glucose-containing medium (Brooks, 1979). Alternatively, the immediate precursor, glucose 6-phosphate (Eisenberg, 1967), may be in high concentration or compartmentalized. This precursor may also arise from epididymal glycogen, which can spare the utilization of glucose in tissue slices and provide lactate in the absence of glucose (Brooks, 1978). In support of this, the total activity of phosphorylase exceeds that of hexokinase (Brooks, 1976a), and intracellular glycogen is lost after castration (Cavazos, 1958) when inositol secretion is reduced (Pholpramool, White \& Setchell, 1982). On the other hand, the conversion of inositol to phosphatidylinositol by caudal tissue and epithelium from the vas deferens in vitro (Voglmayr, 1974) reveals phospholipid as a possible alternative store of inositol.

Data on glucose movement across the epithelium were also obtained from these experiments. The absolute concentration of glucose in the lumen was much lower than that found in vivo (Cooper \& Waites, 1979; Cooper, 1982) when blood levels were higher than the bath levels in the present studies. The bath was shown to be the sole source of luminal glucose and transport into the lumen was linearly related to concentration in the bath suggesting a diffusion process. Taking into consideration leakage and metabolism, the specific movement of labelled glucose to the lumen was about $9 \%$ that of the bath amount, a little above the value obtained in vivo $(1-7 \%)$ for which the similar entry to the lumen of radioactivity arising from $\left[{ }^{14} \mathrm{C}\right]$ glucose and the non-metabolizable $\left[{ }^{3} \mathrm{H}\right] 3-O$-methylglucose suggested little metabolism of glucose in the epididymis of a different strain of rats (Cooper \& Waites, 1979). The discrepancy between rates of secretion and transport of glucose in the present study may reflect inadequate separation of secreted metabolites from glucose.

The greater entry of tracer to the lumen of the cauda when glucose concentrations in the bath were reduced provides further evidence for the presence of carriers for facilitated diffusion in the basal membrane deduced from work on tissue slices (Brooks, 1978, 1979) and the reduced movement of circulating $\left[{ }^{3} \mathrm{H}\right]-3-O$-methylglucose to caput epididymal fluid when blood glucose was raised (Hinton \& Howards, 1982). Equally, the increased luminal movement of tracer, when the normal concentration gradient of glucose across the epithelium was reversed, can be explained by exchange-diffusion, whereby flux by mobile carriers in the apical membrane is increased by movement of sugar from the lumen into the cell. Glucose, unlike inositol, is removed when perfused through the lumen in vivo (Cooper, 1982).

The results suggest that carriers facilitate the diffusion of glucose from the bath fluid to the epididymal lumen across both cell membranes of epididymal epithelial cells, whereas inositol is pumped against a concentration gradient into the cell and secretion into the lumen is augmented by synthesis or release from an unidentified source.

We thank the W.H.O. Special Programme of Research in Human Reproduction and the State Family Planning Commission of China for making this research possible and Xing Zhijun and Mrs B. Parker for typing the manuscript. T.G.C. was a Consultant for U.N. project HRP/CPR/80/P07. 


\section{References}

Brooks, D.E. (1976a) Activity and androgenic control of glycolytic enzymes in the epididymis and epididymal spermatozoa of the rat. Biochem. J. 156, 527-537.

Brooks, D.E. (1976b) Changes in the composition of the excurrent duct system of the rat testis during post natal development. $J$. Reprod. Fert. 46, 31-38.

Brooks, D.E. (1978) Androgen regulation of metabolic pathways in the rat epididymis. Biol. Reprod. 18, 629 638.

Brooks, D.E. (1979) Carbohydrate metabolism in the rat epididymis; evidence that glucose is taken up by tissue slices and isolated cells by a process of facilitated transport. Biol. Reprod. 21, 19-26.

Cavazos, L.F. (1958) Effects of testosterone propionate on histochemical reactions of epithelium on rat ductus epididymidis. Anat. Rec. 132, 209-227.

Cooper, T.G. (1982) Secretion of inositol and glucose by the perfused rat cauda epdidymidis. J. Reprod. Fert. 64, 373-379.

Cooper, T.G. \& Waites, G.M.H. (1979) Investigation by luminal perfusion of the transfer of compounds into the epididymis of the anaesthetized rat. J. Reprod. Fert. 56, 159-164.

Cooper, T.G. \& Waites, G.M.H. (1980) Role of proteins in the transport of steroids into the epididymis. In Testicular Development, Structure, and Function, pp. 299-304. Eds A. Steinberger \& E. Steinberger. Raven Press, New York.

Cooper, T.G., Yeung, C.H. \& Wu, Y.W. (1985) Epididymal function studied by in vitro luminal perfusion. Reproduction and Contraception Sinica (in press) [In Chinese.]

Dacheux, J.L. (1980) An in-vitro luminal perfusion technique to study epididymal secretion. IRCS Med. Sci. 8, 137.

Eisenberg, F. (1967) D-myo-inositol-1-phosphate as a product of cyclization of glucose-6-phosphate and substrate for a specific phosphatase in rat testis. $J$. biol. Chem. 242, 1375-1382.

Eisenberg, F. \& Bolden, A.H. (1964) Reproductive tract as site of synthesis and secretion of inositol in the male rat. Nature, Lond. 202, 599-600.

Hammerstedt, R.H. (1975) Tritium release from $\left[2-{ }^{3} \mathrm{H}\right] \mathrm{D}$ glucose as a monitor of glucose consumption by bovine sperm. Biol. Reprod. 12, 545-551.

Hasegawa, R. \& Eisenberg, F. (1981) Selective hormonal control of myo-inositol biosynthesis in reproductive organs and liver of the male rat. Proc. natn. Acad. Sci. U.S.A. 78, 4863-4866.

Hinton, B.T. \& Howards, S.S. (1981) Permeability characteristics of the epithelium in the rat caput epididymis. J. Reprod. Fert. 63, 95-99.

Hinton, B.T. \& Howards, S.S. (1982) Rat testis and epididymis can transport $\left[{ }^{3} \mathrm{H}\right] 3-\mathrm{O}$-methyl-D-glucose, $\left[{ }^{3} \mathrm{H}\right]$ inositol and $\left[{ }^{3} \mathrm{H}\right] \alpha$-aminoisobutyric acid across its epithelia in vivo. Biol. Reprod. 27, 1181-1189.
Hinton, B.T., White, R.W. \& Setchell, B.P. (1980) Concentration of myo-inositol in the luminal fluid of the mammalian testis and epididymis. $J$. Reprod. Fert. 58, 395-399.

Hoffer, A.P. \& Hinton, B.T. (1984) Morphological evidence for a blood-epididymis barrier and the effects of gossypol on its integrity. Biol. Reprod. 30, 991-1004.

Johansen, L. \& Behmer, J. (1979) Uptake of $\left[{ }^{3} \mathrm{H}\right]-\mathrm{L}-$ carnitine by isolated rat epididymal tubules. Archs Androl. 2, 117-121.

Kormano, M. (1968) Microvascular structure of the rat epididymis. Annls Med. exp. Biol. Fenn. 46, 113-118.

Loewus, M.W., Wright, R.W., Bondioli, K.R., Bedgak, D.L. \& Karl, A. (1983) Activity of myo-inositol-1phosphate synthase in the epididymal spermatozoa of rams. J. Reprod. Fert. 69, 215-220.

Maeda, T. \& Eisenberg, F. (1980) Purification, structure, and catalytic properties of L-myo-inositol-1-phosphate synthase from rat testis. J. biol. Chem. 255, 8458-8464.

Pholpramool, C., White, R.W. \& Setchell, B.P. (1982) Influence of androgens on inositol secretion and sperm transport in the epididymis of rats. J. Reprod. Fert. 66, 547-553.

Reid, B.L. \& Cleland, K.W. (1957) The structure and function of the epididymis. I. The histology of the rat epididymis. Aust. J. Zool. 5, 223-246.

Roberts, M.L., Scouten, W.H. \& Nyquist, S.E. (1976) Isolation and characterization of the cytoplasmic droplet in the rat. Biol. Reprod. 14, 421-424.

Robinson, R. \& Fritz, I.B. (1979) Myoinositol biosynthesis by Sertoli cells, and levels of myo-inositol biosynthetic enzymes in the testis and epididymis. Can. J. biol. Chem. 57, 962-967.

Setchell, B.P. \& Hinton, B.T. (1981) The effects on the spermatozoa of changes in the composition of luminal fluid as it passes along the epididymis. In Epididymis and Fertility: Biology and Pathology. pp. 58-66. Eds C. Bollack \& A. Clavert. S. Karger, Basel.

Suzuki, F. (1982) Microvasculature of the mouse testis and excurrent duct system. Am. J. Anat. 163, 309325.

Voglmayr, J.K. (1974) Alpha-chlorohydrin-induced changes in the distribution of free myo-inositol and prostaglandin $F_{2 a}$, and synthesis of phosphatidylinositol in the rat epididymis. Biol. Reprod. 11, 593-600.

Wong, P.Y.D., Au, C.L. \& Ngai, H.K. (1980) The isolated duct of the rat cauda epididymidis as a model for isosmotic transport studies. Jap. J. Physiol. 30,1-15.

Yeung, C.H., Cooper, T.G. \& Waites, G.M.H. (1980) Carnitine transport into the perfused rat epididymis regional differences, stereospecificity, stimulation by choline, and the effect of other luminal factors. Biol. Reprod. 23, 294-304. 